\title{
Considerações gerais sobre o tratado Modus curandi cum balsamo
}

\author{
General observations on the treatise \\ Modus curandi cum balsamo
}

\author{
Ana Thereza Basílio Vieira \\ Professora do Programa de Pós-Graduação em Letras Clássicas da UFRJ \\ Rua Barata Ribeiro, 283/403 \\ 22040-000 Rio de Janeiro - RJ - Brasil \\ atherezavieira@aol.com \\ Henrique Cairus \\ Professor do Programa de Pós-Graduação em Letras Clássicas da UFRJ \\ Rua Doutor Júlio Otoni, 278/fds. 1 \\ 20241-100 Rio de Janeiro - RJ - Brasil \\ hcairus@ufrj.br
}

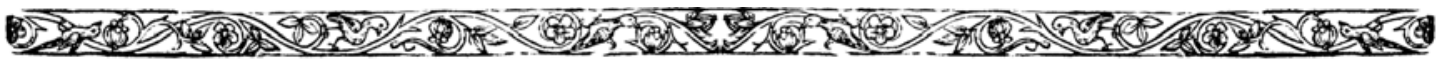

BASÍLIO VIEIRA, A. T.; CAIRUS, H.: Considerações gerais sobre o tratado Modus curandi cum balsamo. História, Ciências, Saúde - Manguinhos, v. 12, n. 3, p. 829-31, set.-dez. 2005.

O Modus curandi cum balsamo é um texto breve, impresso em c.1530, escrito em baixo latim ibérico e de autor desconhecido. O que o torna importante à primeira vista é o fato de ter sido este um dos primeiros textos médicos impressos em Portugal. Mas definitivamente tem valores outros que sustentam até mesmo essa sua primazia. Apresenta um bálsamo, como o título indica, que é capaz de curar especialmente feridas profundas. Sua receita é peculiar, e mais peculiar ainda é o tom propagandístico do breve tratado. Além da receita, fornecem-nos recomendacões de como aplicá-lo, especialmente no crânio, do qual se fala de uma ferida que vai da dura-máter à 'substância' da cabeça, e tal ferida, segundo o tratado, deve ser previamente drenada para a aplicação do bálsamo.

PALAVRAS-CHAVE: Bálsamo; textos médicos renascentistas; feridas profundas no Renascimento português.

BASÍLIO VIEIRA, A. T.; CAIRUS, H.: General observations on the treatise Modus curandi cum balsamo. História, Ciências, Saúde - Manguinhos, v. 12, n. 3, p. 829-31, Sept.-Dec. 2005.

Modus curandi cum balsamo is a short text, printed circa 1530 and written by an unknown author in Vulgar Latin from the Iberian peninsula. Its value stems first from the fact that it was one of the first medical texts printed in Portugal. But other aspects definitely reinforce this importance. As the title indicates, the text describes a balm that can cure very deep wounds. The prescription is strange, and even stranger is the propagandizing tone of this brief treatise. The prescription comes with recommendations on how to apply the remedy, especially to the cranium. Reference is made to a wound that goes from the dura mater to the "substance" of the head; according to the treatise, this wound should first be drained before applying the balm.

KEYWORDS: balm; Renaissance medical texts; deep wounds during the Portuguese Renaissance. 
$\mathrm{N}$ o século XII, o erudito ibérico Gerardus Cremonensis (Gerardo de Cremona) verteu para o latim a introdução do Método terapêutico, de Galeno. Sua tradução, feita a partir do árabe, teve uma importância capital e crescente para o estudo da medicina.

O título dado por Gerardo de Cremona à sua tradução, De ingenio sanitatis, ${ }^{1}$ deu nova direção à leitura dos textos médicos, reconciliando a prática da medicina com o eruditismo universitário que ascendia.

A expressão ingenium sanitatis, assim como sua variante, ingenium curativum, constituiu-se na palavra de ordem evocada nos séculos XIV e XV - sobretudo na Península Ibérica - para falar acerca do processo pelo qual o médico passa da reflexão à ação.

O êxito na circulação desse texto galênico deveu-se a alguns fatores, que vão desde o renome do tradutor, que estava associado aos grandes clássicos do que chamamos de história da ciência na Antiguidade, até a própria lavra de Galeno. A fluência da circulação do texto De ingenio sanitatis deveu-se também à premência de se descer dos princípios gerais ao particular.

A palavra ingenium traz à mente a idéia de um artifício ou de uma prática artificiosa tendo em vista um fim específico.

O opúsculo que se segue é uma amostra do ingenium sanitatis uel curativum. Insere-se nesse movimento da história da medicina ibérica que procura engendrar a prática a partir de postulados livrescos inscritos no universo de erudição em grande parte associado ao desvelamento do saber erudito a partir da tradução dos sábios árabes e de suas versões das obras gregas.

Junto com o tratado sobre a Pestilença, que integra o presente volume, o De modus curandi cum balsamo forma toda a produção editorial impressa da área médica do Portugal do século XV. Trata-se de um pequeno manual dividido em quatro partes: como fazer curativos com bálsamo e, em seguida, como proceder no caso de três tipos de feridas: no peito, feridas internas e, por último, na cabeça.

Algumas peculiaridades podem ser notadas no Modus curandi cum balsamo. Para começar, seus postulados não são absolutamente claros, mas pode-se ler a palavra "doutores" (nas duas ocorrências da expressão "sicut precipiunt doctores"). Pode-se dizer que a formulação dos postulados gerais cede lugar à nomeação dos baluartes desse saber teórico. Isso nos leva a pensar que a escolha do verbo precipio (praecipio, no latim clássico) reverbera seu significado de "estar à frente", de "vir antes", donde deriva a acepção de "recomendar". Temos, assim, um autor que se coloca entre o saber de um grupo a que ele mesmo designa de "doutores" e o não-saber do paciente, inscrevendo-se, por conseguinte, no ingenium curativum, que procurará praticar em seu pequeno texto.

O opúsculo é escrito em um baixo latim ibérico tardio, por vezes muito próximo ao vernáculo de então, a julgar pelos indícios de oralidade e principalmente pela similitude com os textos vernaculares coevos que nos chegaram. Conservam-se determinadas estruturas do latim clássico, ora por serem expressões cristalizadas, ora por serem simplesmente formulares. Mesmo o que se poderia interpretar como um traço esvanecido da retórica clássica, como o paralelismo sintático estilístico, pode também ter outra leitura, que explique tal ou qual estrutura, supondo proximidade com algum coloquialismo. De fato, os argumentos em prol da influência da coloquialidade fazem-se patentes na ordem dos elementos das frases, no vocabulário, no tipo de anáfora e, sobretudo, no estilo e no andamento oralizado, abundante em marcadores discursivos de continuidade, especialmente o "et". 
Nenhuma dessas observações, porém, aplica-se ao "Prologus", definitivamente a parte de leitura mais difícil, onde não se pode recorrer nem aos parâmetros do latim clássico nem ao auxílio da comparação com as línguas ibéricas, dado o seu grau de artificialidade lingüística. Isso torna o texto semanticamente opaco e, por conseqüência, um desafio de tradução que só pôde ser superado graças à argúcia de Ana Thereza Basílio Vieira, docente do Programa de Pós-Graduação em Letras Clássicas e especialista em textos latinos dos séculos XV e XVI, que co-assina a tradução do texto. A decifração da receita do bálsamo deveu-se à erudição de Diana Maul de Carvalho, da Faculdade de Medicina da UFRJ. O fac-símile sobre o qual trabalhamos foi fruto da pesquisa de Maria Carlota Paixão Amaral Rosa, do Programa de Pós-Graduação em Lingüística da UFRJ.

A tipografia do texto original é muito oscilante nos fartos usos que faz das abreviaturas. Certamente, uma abreviatura pode ter mais de uma leitura (e, nesse caso, supõe-se a possível dedução), mas também uma letra pode ter mais de uma forma. É o caso do ' $m$ ', que figura com três formas, uma das quais partilhada com o ' $n$ '. Claro que essas formas não eram usadas de modo completamente arbitrário. No caso do ' $\mathrm{m}$ ', uma é sempre constante para início de sílaba, enquanto outra era usada para fim de sílaba, e a terceira, exclusivamente para fim de vocábulo (onde concorria com a segunda). As marcas de pontuação da tipografia da época foram investigadas em um denso ensaio crítico por Maria Carlota Paixão Amaral Rosa, ${ }^{2}$ que estudou o que havia por trás de cada sinal de pontuação, se uma marca de oralidade ou se a preocupação em demarcar fronteiras sintáticas. Seja como for, pode-se assegurar que os sinais de pontuação da pequena obra ora reeditada são diversos dos nossos tanto na forma quanto no uso, e bem mereceram o estudo que lhes foi devotado.

\section{NOTAS}

\footnotetext{
${ }^{1}$ Jacquar, D. L'enseignement de la médecine: quelques termes fondamentaux. In: Weijers, U. Méthodes et instruments du travail intellectuel au Moyen Age: études sur le vocabulaire. Turnhout, 1990.

2 Rosa, Maria Carlota Amaral Paixão. Pontuação de sintaxe em impressos portugueses renascentistas. Tese de Doutorado em Lingüística, UFRJ, Rio de Janeiro, 1994.
} 


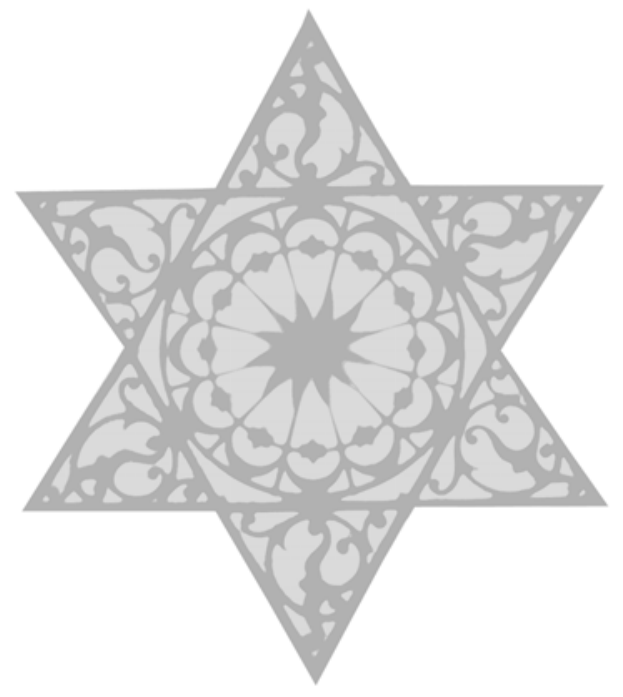

